\title{
A Clinico-Radiological Correlation of Shoulder Joint Pain Original Article
}

\author{
Dr. Anil U Madurwar ${ }^{1}$, Dr. Sravan kumar .K ${ }^{2}$, Dr. Ramya ${ }^{3}$, Dr. Bhavani ${ }^{4}$ \\ ${ }^{1}$ Professor, Department of Radiodiagnosis , Chalmeda, Ananda Rao Institute of Medical Sciences and Hospital, Karimnagar \\ ${ }^{2}$ Post Graduate, Department of Radiodiagnosis , Chalmeda, Ananda Rao Institute of Medical Sciences and Hospital, Karimnagar \\ ${ }^{3}$ Post Graduate, Department of Radiodiagnosis , Chalmeda, Ananda Rao Institute of Medical Sciences and Hospital, Karimnagar \\ ${ }^{4}$ Post Graduate, Department of Radiodiagnosis , Chalmeda, Ananda Rao Institute of Medical Sciences and Hospital, Karimnagar
}

\begin{abstract}
Background: Shoulder pain is one of the commonest conditions encountered in our orthopedic department. Accurate diagnosis is a must before undertaking any treatment. Since clinical diagnosis cannot make an accurate diagnosis, radiological investigation is necessary to know the exact cause of shoulder pain. There are a wide range of invasive and non-invasive modalities that can be used to investigate these patients. Though MR arthrography is said to be the gold standard for investigating patients with shoulder pain, being invasive and expensive, generally not used as a first line of investigation. Hence non-invasive imaging like USG and conventional MRI should be used. Aims and objectives: To evaluate a patient with shoulder joint pain in terms of: Assessment by Ultrasound as the first line of imaging modality as compared to MRI. Comparing the accuracy of ultrasonography in shoulder joint pathologies by comparing its findings with those of Magnetic Resonance Imaging performed subsequently on the same patient. To delineate pitfalls during image interpretation and limitation of USG and MRI. Methods: Prospective analysis of 30 patients presenting with shoulder pain were included in our study. A pre-formed written consent is also taken. All patients underwent a thorough clinical examination, followed by X-ray (AP) of the affected shoulder, USG of the affected shoulder with comparison of the opposite side and MRI of the affected shoulder for comparison. Results: Ultrasound is equivalent in detection of rotator cuff tears in comparison with MRI. MRI outscores ultrasound in detection of labral tears, cartilaginous lesions and subtle bony lesions. Interpretation and conclusion: USG examination can be used as the first line of investigating a case of shoulder pain as it is inexpensive, real time and allows for comparison with the opposite side. MRI can be used as a confirmatory tool or in problematic cases.
\end{abstract}

Keywords: Ultrasound; Magnetic Resonance Imaging; Rotator cuff;

\section{Introduction}

Shoulder pain is one of the most common complaints encountered in orthopedic practice and often leads to considerable disability. There are various causes of a painful shoulder, but periarticular soft tissue lesions involving tendons and bursae are the most common and are often associated with chronic impingement of the rotator cuff on the anterolateral margin of the acromion. Even though a large amount of clinical tests used for the diagnosis of painful shoulder are considered accurate in determining the location of the periarticular lesions, these entities may be difficult to differentiate by physical examination. ${ }^{[1]}$ Clinical diagnosis have low accuracy in comparison with arthroscopy. ${ }^{[\mathbf{1 , 2}]}$

High resolution ultrasound is non invasive, less expensive and non-ionizing modality with good sensitivity in detecting both rotator cuff and non rotator cuff disorder. ${ }^{[3]}$ It serves as a complementary role to magnetic resonance imaging of the shoulder. The reported accuracy, sensitivity and specificity of high resolution ultrasound in the detecting of any tear, whether partial or full thickness are all greater than $90 \%$.

The lesions of the rotator cuff are common cause of shoulder pain and dysfunction. Cuff strain, Impingement syndrome, Rotator cuff tears make up a group of lesions that produce shoulder pain. It is clinically difficult to differentiate between these diagnosis and distinguish cuff problems from other conditions like Glenohumeral instability. Hence, it is the commonest musculoskeletal ultrasound examination request. Improvement in the resolution of ultrasound machines, redefined technique and better understanding of the pathology have contributed to its high accuracy in the diagnosis of rotator cuff pathology.

Magnetic Resonance Imaging and Ultrasonography have replaced arthrography for evaluating the integrity of the rotator cuff. ${ }^{[4]}$ Magnetic Resonance arthrography is used for instability. ${ }^{[5]}$

MRI has become the "gold standard" for detecting both subtle and obvious internal derangement and assessing overall joint structure. $^{3}$ MRI is an excellent modality because of its multiplanar capability. Finding a correlation between symptoms and images is a challenging task and is essential to ensure that the imaging findings explain the symptoms and can be used to adjust the therapy

\section{Methodology}

A prospective study of thirty patients with shoulder pain was undertaken in the department of Radio-diagnosis during a period from December 2014 to June 2016.

\section{Inclusion criteria}

- Age $>40$ yrs.

- History of pain in either shoulder joint.

- History of trauma (trivial).

- Clinically suspected to have a rotator cuff injury (full 


\section{International Journal of Science and Research (IJSR) \\ ISSN (Online): 2319-7064}

Index Copernicus Value (2015): 78.96 | Impact Factor (2015): 6.391

thickness or partial thickness tears), biceps tendon injury, or calcific tendinitis.

\section{Exclusion criteria}

- Clinically suspected cases of instability.

- Known cases of Rheumatoid arthritis

- Previous surgery or prosthesis of shoulder.

- Patients with pace makers, metal implants in their bodies, foreign bodies in their eyes and those having claustrophobia.

These patients were initially clinically examined by the orthopeditian and then radiologically evaluated. The radiological examinations that were undertaken are an antero-posterior $\mathrm{x}$-ray of the involved shoulder joint, followed by an USG examination with comparison of the opposite shoulder and then a MRI of the affected shoulder

Antero-posterior X-ray: Initially a plain Antero-posterior $\mathrm{X}$-ray radiogram of the affected shoulder joint was done, using a GE Tejas 6000 with Fuji CR system or a 1000 MA Shimadzu X-ray. Findings such as cystic formation or erosions in the tuberosities, degenerative changes in the ACJ, humeral head and glenoid, calcifications in the region of the rotator cuff were documented.

Ultrasound examination of the shoulder: The examination on the affected shoulder was carried out on a GE Voluson 730 , with a high frequency linear transducer of 6-12 MHz. The rotator cuff tendons and muscles were examined in various positions, the ACJ and the posterior aspect of the joint was also examined. Dynamic examinations of the shoulder were also carried out. Comparison of the opposite shoulder was also done.

MRI of the affected shoulder: The MRI examination was performed on a 1.5 Tesla GE SIGNA HDxt, with a Flex C1 coil centered over the affected shoulder with the patient in supine position. Multiplanar images were obtained in the axial, oblique coronal and oblique sagittal planes.

The sequences used were:

- Short T1 inversion recovery (STIR) in the axial plane, a slice thickness of 3mm, a FOV of $150 \mathrm{~mm}$ and TR/TE 7913/170.

- Proton density images in the oblique coronal plane, a slice thickness of $3 \mathrm{~mm}$, a FOV of $140 \mathrm{~mm}$ and TR/TE 4500/30.

- T2 weighted images in the oblique coronal plane, a slice thickness of $3 \mathrm{~mm}$, a FOV of $140 \mathrm{~mm}$ and TR/TE 4375/100.

- T2 images in the oblique coronal plane, a slice thickness of $3 \mathrm{~mm}$, a FOV of $140 \mathrm{~mm}$ and TR/TE - 4000/50.

- Proton density images in the oblique sagittal plane, a slice thickness of $3 \mathrm{~mm}$, a FOV of $140 \mathrm{~mm}$ and TR/TE 4500/30.

- Short T1 inversion recovery (STIR) images in the oblique sagittal plane, a slice thickness of $3 \mathrm{~mm}$, a FOV of $140 \mathrm{~mm}$ and TR/TE - 3443/60.

\section{Statistical Methods}

Descriptive statistical analysis has been carried out in the present study. Results on continuous measurements are presented on Mean \pm SD (Min-Max) and results on categorical measurements are presented in Number (\%). Significance is assessed at $5 \%$ level of significance. Chisquare/ Fisher Exact test has been used to find the significance of study parameters on categorical scale between two or more groups. Diagnostic statistics viz. Sensitivity, Specificity, PPV, NPV and Accuracy have been computed to find the correlation of USG with MRI findings.

\section{1) Chi-Square Test}

$\chi^{2}=\sum(O i=\underline{E i) 2}$, Where Oi is Observed frequency and Ei is Expected frequency

\section{2) Fisher Exact Test}

\begin{tabular}{|c|c|c|c|}
\hline & Class1 & Class2 & Total \\
\hline Sample1 & A & B & $\mathrm{a}+\mathrm{b}$ \\
\hline Sample2 & C & D & $\mathrm{c}+\mathrm{d}$ \\
\hline Total & $\mathrm{a}+\mathrm{c}$ & $\mathrm{b}+\mathrm{d}$ & $\mathrm{n}$ \\
\hline
\end{tabular}

$$
2 \times 2 \text {.Fisher Exact Test statistic }=\Sigma p=\frac{(a+b) !(c+d) !(a+c) !(b+d) !}{n !} \sum a ! b ! c ! d !
$$

\section{3) Diagnostic Statistics}

\begin{tabular}{|c|c|c|c|c|c|}
\hline & Disease & \multicolumn{3}{|c|}{} \\
\hline Test & Present & N & Absent & n & Total \\
\hline Positive & True Positive & $A$ & False Positive & $c$ & $a+c$ \\
\hline Negative & False Negative & $B$ & True Negative & $d$ & $b+d$ \\
\hline Total & & $a+b$ & & $c+d$ & \\
\hline
\end{tabular}

The following statistics can be defined:

- Sensitivity: probability that a test result will be positive when the disease is present (true positive rate, expressed as a percentage $)=\mathrm{a} /(\mathrm{a}+\mathrm{b})$

- Specificity: probability that a test result will be negative when the disease is not present (true negative rate, expressed as a percentage $)=\mathrm{d} /(\mathrm{c}+\mathrm{d})$
- Positive predictive value: probability that the disease is present when the test is positive (expressed as a percentage $)=\mathrm{a} /(\mathrm{a}+\mathrm{c})$

- Negative predictive value: probability that the disease is not present when the test is negative (expressed as a percentage $)=\mathrm{d} /(\mathrm{b}+\mathrm{d})$

- Accuracy is the sum of true positive and True negative divided by number of cases

\section{Diagnostic values based on Area under curve}

0.9-1.0: Excellent test

0.8-0.9: Good test

0.7-0.8: Fair test

0.6-0.7: Poor test

0.5-0.6: Fail 
International Journal of Science and Research (IJSR)

ISSN (Online): 2319-7064

Index Copernicus Value (2015): 78.96 | Impact Factor (2015): 6.391

Significant figures

\begin{tabular}{|c|c|c|}
\hline+ & Suggestive significance & $($ Pvalue: $0.05<\mathrm{P}<0.10)$ \\
\hline$*$ & Moderately significant & $(\mathrm{P}$ value: $0.01<\mathrm{P} 0.05)$ \\
\hline$* *$ & Strongly significant & $(\mathrm{P}$ value: $\mathrm{P} \leq 0.01)$ \\
\hline
\end{tabular}

Statistical software: The Statistical software namely SAS 9.2, SPSS 15.0, Stata 10.1, MedCalc 9.0.1, Systat 12.0 and R environment ver.2.11.1 were used for the analysis of the data and Microsoft Word and Excel have been used to generate graphs, tables etc.

\section{Results and Observations}

\section{Study Design}

A clinico-radiological correlation of 30 patients with shoulder joint pain was undertaken to study the correlation of USG finding with MRI findings.

X-ray A-P view of shoulder was taken which showed cystic changes in $16.7 \%$, erosions of humeral head in $3.3 \%$, degenerative changes of head of humerus in $16.7 \%$, calcifications of rotator cuff in $3.3 \%$ of patients as shown in (table 1) and thus has a limited role in the evaluation of shoulder pain.

Ultrasound showed that supraspinatus is the most common tendon for partial thickness, full thickness tears and tendinosis accounting for 11(36.7\%), 4(13.3\%) and $7(23.3 \%)$ of patients followed by subscapularis tendon as shown in (table 2). Bursitis is most common in subacromialsubdeltoid bursa accounting for $7(23.3 \%)$ of patients as in table. On ultrasound ACJ hypertrophy is seen in 2() of patients as in table

The sensitivity, specificity, PPV, NPV and accuracy of USG with MRI as gold standard were $76.9 \%, 50 \%, 90.9 \%, 25 \%$ and $73.3 \%$ for supraspinatus tendon and $50 \%, 92.8 \%, 33.3 \%, 96.3 \%$ and $90 \%$ for subscapularis tendon as shown in table

\begin{tabular}{|c|c|c|c|}
\hline \multicolumn{4}{|c|}{ X-ray findings } \\
\hline$X$-ray findings & Criteria & $\begin{array}{c}\text { Number of } \\
\text { patients }(n=30)\end{array}$ & $\%$ \\
\hline \multirow{2}{*}{$\begin{array}{l}\text { Cystic changes of the } \\
\text { tuberosities of the humerus } \\
\text { tuberosities of the }\end{array}$} & Absent & 25 & 83.3 \\
\hline & Present & 5 & 16.7 \\
\hline \multirow{2}{*}{$\begin{array}{c}\text { Erosions of the tuberosities of } \\
\text { the Humerus }\end{array}$} & Absent & 29 & 96.7 \\
\hline & Present & 1 & 3.3 \\
\hline \multirow{2}{*}{ Acromio - clavicular Lesions } & Absent & 22 & 73.3 \\
\hline & Present & 8 & 26.7 \\
\hline \multirow{2}{*}{$\begin{array}{l}\text { Degenerative changes of the } \\
\text { glenoid }\end{array}$} & Absent & 30 & 100 \\
\hline & Present & 0 & 0 \\
\hline \multirow{2}{*}{$\begin{array}{c}\text { Degenerative changes of the } \\
\text { humeral head }\end{array}$} & Absent & 25 & 83.3 \\
\hline & \begin{tabular}{|l|} 
Present \\
\end{tabular} & 5 & 16.7 \\
\hline \multirow{2}{*}{$\begin{array}{c}\text { Calcification of the Rotator } \\
\text { Cuff }\end{array}$} & Absent & 29 & 96.7 \\
\hline & Present & 1 & 3.3 \\
\hline
\end{tabular}

Ultrasound findings: Pathology (Tear)

\begin{tabular}{|c|c|c|c|c|c|}
\hline \multirow{2}{*}{$\begin{array}{c}\text { Tendons } \\
(\mathrm{n}=30)\end{array}$} & $\begin{array}{c}\text { Partial } \\
\text { Thickness } \\
\text { tear }\end{array}$ & $\begin{array}{c}\text { Full } \\
\text { Thickness } \\
\text { tear }\end{array}$ & Tendinosis & $\begin{array}{c}\text { Intra- } \\
\text { substance } \\
\text { teartear }\end{array}$ & Normal \\
\hline Subscapularis & $2(6.7 \%)$ & 0 & $1(3.3 \%)$ & 0 & $27(90.0 \%)$ \\
\hline Supraspinatus & $11(36.7 \%)$ & $4(13.3 \%)$ & $7(23.3 \%)$ & 0 & $8(26.7 \%)$ \\
\hline Infraspinatus & 0 & 0 & 0 & 0 & $30(100.0 \%)$ \\
\hline Teres Minor & 0 & 0 & 0 & 0 & $30(100.0 \%)$ \\
\hline $\begin{array}{c}\text { Biceps } \\
\text { Tendon }\end{array}$ & 0 & 0 & 0 & 0 & $30(100.0 \%)$ \\
\hline
\end{tabular}

Ultrasound findings: Bursal Fluid / Bursitis

\begin{tabular}{|c|c|c|c|}
\hline Bursa & Criteria & $\begin{array}{c}\text { Number of patients } \\
(n=30)\end{array}$ & $\%$ \\
\hline $\begin{array}{c}\text { Subacromial- } \\
\text { subdeltoid bursa }\end{array}$ & Absent & 23 & 76.7 \\
\cline { 2 - 4 } & Present & 7 & 23.3 \\
\hline $\begin{array}{c}\text { Subcoracoid } \\
\text { bursa }\end{array}$ & Absent & 30 & 100 \\
\cline { 2 - 4 } & Present & 0 & 0 \\
\hline
\end{tabular}

Table 15: USG findings: ACJ hypertrophy

\begin{tabular}{|c|c|c|c|}
\hline & & Number of patients $(n=30)$ & $\%$ \\
\hline ACJ & Absent & 28 & 93.3 \\
\cline { 2 - 4 } hypertrophy & Present & 2 & 6.7 \\
\hline
\end{tabular}

Correlation of USG findings with MRI findings: An Evaluation

\begin{tabular}{|c|c|c|c|c|c|c|}
\hline Findings & Sensitivity & Specificity & $P P V$ & NPV & Accuracy & $\begin{array}{c}P \\
\text { Value }\end{array}$ \\
\hline 1.Subscapularis & 50 & 92.86 & 33.33 & 96.3 & 90 & $0.051+$ \\
\hline 2.Supraspinatus & 76.92 & 50 & 90.91 & 25 & 73.33 & 0.257 \\
\hline 3.Infraspinatus & 0 & 100 & 50 & 96.67 & 96.67 & NS \\
\hline 4.Teres Minor & 0 & 100 & 50 & 100 & 100 & NS \\
\hline 5.Biceps Tendon & 0 & 100 & 50 & 96.67 & 96.67 & NS \\
\hline $\begin{array}{c}\text { 6.Peribicipital } \\
\text { Tendon Fluid }\end{array}$ & 41.67 & 83.33 & 90.91 & 26.32 & 50 & 0.255 \\
\hline $\begin{array}{c}\text { 7.Subacromial- } \\
\text { ubdeltoid bursitis }\end{array}$ & 26.09 & 85.71 & 85.71 & 26.09 & 40 & 0.519 \\
\hline $\begin{array}{c}\text { 8.Subcoracoid } \\
\text { bursitis }\end{array}$ & 0 & 100 & 50 & 46.67 & 46.67 & NS \\
\hline
\end{tabular}

\section{Discussion}

Various techniques are used for evaluating patients with shoulder pain including clinical examination, X-ray, arthrography, USG, CT scan and MRI. The most accurate is MR arthrography. Conventional MRI is sensitive and specific, but cannot be used as a first line of investigation. However, USG is a non-invasive, relatively inexpensive modality that can be used.

This was a prospective study of 30 patients who presented with shoulder pain. A detailed history and clinical examination was done initially, following which an X-ray (AP) of the affected shoulder was done. An USG examination of the affected shoulder with comparison to the opposite side was done. These findings were correlated with MRI.

Our study group comprised of 30 patients who were above 40 years of age, with mean age of 49.77 (S.D \pm 10.27 ) years. The gender distribution in our study showed a male preponderance, of 16 males (53.3\%) and 14 females $(46.7 \%)$. Only 5 patients $(16.67 \%)$ had a history of trauma to

\section{Volume 6 Issue 7, July 2017 www.ijsr.net}




\section{International Journal of Science and Research (IJSR) \\ ISSN (Online): 2319-7064 \\ Index Copernicus Value (2015): 78.96 | Impact Factor (2015): 6.391}

the affected shoulder. A history of diabetes was present in 9 $(30.0 \%)$ of our patients.

On clinical examination tenderness was present in 5 $(16.67 \%)$ of the patients. 13 patients $(43.3 \%)$ had normal range of motion, whereas restricted range of motion was seen in 17 patients $(56.7 \%)$. A positive Neer's Test was present in 17 patients $(56.7 \%)$.

Shalene A. Teefey (1999) stated that shoulder ultrasonography was improving over the last decade, with the advent of high frequency probes. He emphasizes on musculoskeletal anatomy, sonographic technique, normal sonographical anatomy, pathophysiology of rotator cuff and biceps tendon disease, and sonographics findings of rotator cuff tears.

Rotator cuff pathologies were the commonest cause of painful shoulder in our study. The pathologies included partial, full thickness tears and tendinosis. Supraspinatus tendon was the commonest tendon to be involved in our study. Where in USG detected 22 patients and MRI detected 26 patients with supraspinatus tendon pathologies. This is comparable to the study by Zlatkin et al where in they found that supraspinatus tendon involvement was present in around $80 \%$ of their cases. ${ }^{39}$ Subscapularis tendon pathologies $50 \%$ sensitivity, $92.6 \%$ specificity, a PPV of $33.33 \%$, a $96.30 \%$ $\mathrm{NPV}$, with an accuracy of $90.0 \%$ and significance of $\mathrm{P}=$ $0.051+$. The supraspinatus tendon pathologies showed $76.92 \%$ sensitivity, $50.0 \%$ specificity, a PPV of $90.91 \%$, a $25.00 \%$ NPV, with an accuracy of $73.33 \%$ and a significance of $\mathrm{P}=0.257$.

The USG criteria for detection of partial thickness tears were focal discontinuity of the tendon either at the bursal or articular margin. USG criteria for full thickness tears were recognized by complete absence of the tendon. The space over the humeral head is filled by the deltoid muscle and a thickened subacromial-subdeltoid bursa. Tendinosis was diagnosed by USG, in the form of thinning of the tendon and heterogeneous echotexture.

MRI criteria for detection of partial thickness tears are characterized by a focal region of fiber discontinuity that is filled with fluid signal. Beside a focal tendon defect, additional findings included surface fraying or changes in tendon caliber, such as attenuation or thickening. MRI criteria for full thickness tears were characterized by tendon discontinuity. Tendon retraction was another sign to detect full thickness tears. The presence of fluid in the subacromial- subdeltoid bursa, although not specific for a full-thickness tear, to be another indirect sign. ${ }^{[6]}$

For partial thickness tears USG had a sensitivity of $92.7 \%$, specificity of $100.0 \%$. In cases with full thickness tears, $100.0 \%$ sensitivity and $96.3 \%$ specificity was achieved.Subacromial - subdeltoid bursitis had a USG pickup rate of $23.3 \%$ and a MRI pickup rate of $76.7 \%$. In our study, SA - SD, 26.09\% sensitivity, $85.71 \%$ specificity, showing that MRI being a better modality than USG in picking up SA-SD bursitis.

In our study, all the patients underwent X-ray, USG and
MRI. The USG findings were correlated with MRI findings. However, MRI additionally picked up labral tears, IGHL thickening and muscle atrophy. In our study, 7 (23\%) cases on USG had subacromial subdeltoid bursitis while MRI detected subacromial subdeltoid bursitis in $23(76 \%)$ cases. No cases of subcoracoid bursitis were detected on USG while MRI detected it in 16 (54\%) of cases. Thus MRI is a better modality than USG in picking up SA-SD bursitis, this is similar to a study by Shrestha et al. ${ }^{[7]}$

In our study, out of 30 patients 6 cases $(20 \%)$ on MRI showed the presence of labral tears. The labral tears were not detected on USG in our study because of inability to adequately visualize the cartilaginous labrum on USG.

In our study, the accuracy, sensitivity, and specificity of USG in the detection of any tear, whether partial or fullthickness, to be greater than $90 \%$. This is similar to study done by Crass et al. ${ }^{[8]}$

Teefey et al ${ }^{[9]}$ in 2004 revealed overall accuracy of USG to be $87 \%$ in correct identification of partial as well as fullthickness tears. These results are in accordance to our study, which shows an overall accuracy $96 \%$.

Of all the lesions detected on USG as well as on MRI, supraspinatus tendon was more commonly involved than infraspinatus or subscapularis tendon. This is comparable to the study done by Zlatkin et al., ${ }^{[10]}$ wherein they found supraspinatus tendon involvement in around $80 \%$ of their cases. The characteristic anatomic location of the supraspinatus tendon is the likely cause. It is located between the greater tuberosity and the acromion process leading to repeated friction during overhead abduction of the shoulder. ${ }^{46}$

In our study out of 30 cases, 11(36\%) cases had partial thickness tears of supraspinatus and 2 cases (6.7\%) had partial thickness tears of subscapularis on USG. While 14 cases $(46 \%)$ had partial thickness tears of supraspinatus and 2 cases $(7 \%)$ had partial thickness tears of subscapularis and 1 case $(3 \%)$ had partial thickness tear of infraspinatus on MRI. this study is similar to this is similar to a study by Rakesh et al. ${ }^{[11]}$

In our study out of 30 cases, 4 cases $(13.3 \%)$ had full thickness supraspinatus tears on USG while $3(10 \%)$ had full thickness supraspinatus tears on MRI whereas study done by Rakesh et al showed $23 \%$ of full thickness supraspinatus tears on mri. No full thickness tears of subscapularis were found. ${ }^{[11]}$

In our study, on USG there was 2 false positive cases probably due to anisotropy related artifacts and 1 false negative case while the 1 false positive MRI was found probably due to magic angle artifact involving the distal most supraspinatus tendon.

On comparison with MRI, USG showed a sensitivity of $100 \%$ and specificity of $96.3 \%$ for full-thickness tears, and a sensitivity of $92.8 \%$ and specificity of $100 \%$ for partialthickness tears. Overall accuracy of USG in detecting tears was $96 \%$. The findings of our study are in line with many 


\section{International Journal of Science and Research (IJSR) \\ ISSN (Online): 2319-7064}

Index Copernicus Value (2015): 78.96 | Impact Factor (2015): 6.391

others in reporting a high level of sensitivity and specificity for full-thickness tears. These results are equivalent to studies conducted by Read and Parker ${ }^{[12]}$ in 1998 and later by Goldberg et al., in 2003. ${ }^{[13]}$ The level of sensitivity and specificity in the diagnosis of partial-thickness tears are also similar to those of Van Holsbeeck et al. ${ }^{[14]}$ (sensitivity 93\%) and Wiener and Seitz ${ }^{[15]}$ (sensitivity $94 \%$ ), but are in contrast to the findings of Teefey (sensitivity 67\%).

USG advantages: It is non-invasive, real-time, multiplanar and non-ionizing. It can be done rapidly without any patient preparation. It is widely available and at a low cost. It has a high spatial resolution.

\section{Pitfalls of USG}

1) Anisotropy: The rotator cuff appears echogenic when the ultrasound beam insonates at $90^{\circ}$ to the long axis of the tendon fibers because the beam is then reflected maximally. The more the angle deviates from this angle, the fewer reflected sound waves will be detected by the transducer. The tendon becomes isoechoic to muscle at angles of $2^{\circ}-7^{\circ}$ and hypoechoic at greater angles. Tendon insertions, where most rotator cuff tears occur, are most vulnerable to the anisotropic artifact due to their curved course. If unaware of this artifact, less experienced scanners could erroneously take this for tendinosis or a partial-thickness rotator cuff tear.

2) Humeral head anomalies like fractures, distorts the anatomy of the rotator cuff.

3) Muscle bulk is not appreciated in USG examinations; hence denervation injuries are not picked up.

4) Axillary lymph nodes are not picked up by dedicated shoulder ultrasound.

5) USG is operator dependant and has a high inter-observer variation and a high learning curve for radiologists.

\section{MRI has both limitations and pitfalls}

The limitations are claustrophobia, obese patients, post surgical metallic implant fixations. It also has a limited spatial resolution.

\section{Pitfalls of MRI}

The magic angle artifact is routinely encountered in MRI examinations of the shoulder. It mostly occurs in T1 weighted images on the coronal plane. The appearance of intermediate signal intensity is seen within the normal supraspinatus tendon on $\mathrm{T} 1$ weighted images. This phenomenon occurs due to the orientation of the tendon fibers with that of the external magnetic field. The normal supraspinatus tendon is oriented 55-60 degrees to the external magnetic field. However, the signal intensity will not increase on $\mathrm{T} 2$ weighted images.

\section{Conclusion}

- Clinical examination of the shoulder joint does not provide adequate insight on the cause of shoulder pain.

- The commonest pathology causing shoulder pain is rotator cuff pathology, like partial or full thickness tears and the next common pathology is ACJ arthritis.

- Subacromial - subdeltoid bursitis is the commonest associated finding.

- Ultrasound has a high sensitivity of $92.86 \%$ and a specificity of $100.0 \%$ for partial thickness tears, and for full thickness tears, sensitivity of $100.0 \%$ and a specificity of $96.30 \%$.

- Trauma was the etiology in only a few patients.

- USG is not as sensitive as MRI in evaluating labral and capsular pathologies.

- MRI is the most sensitive and specific modality for the establishment of shoulder pain.

- MRI can be used in problematic cases, where the diagnosis is doubtful on USG.

- USG imaging can be considered almost equally effective as compared to MRI, in the evaluation of rotator cuff injuries.

- Though operator dependent, a well performed USG can effectively serve as a primary diagnostic method and screening of all painful shoulder joints because it is economic and fast and MRI should be used secondary because it provides more information about the extent of tendons and has lower risk of artifacts.

\section{References}

[1] Naredo E, Aguado P, De Miguel E, Uson J, et al. Painful shoulder: comparison of physical examination and ultrasonographic findings. Ann Rheum Dis 2002; 61:132-136.

[2] J Nørregaard, M R Krogsgaard, T Lorenzen, E M Jensen. Diagnosing patients with longstanding shoulder joint pain. Ann Rheum Dis 2002; 61:646-649.

[3] Arun Kinare. Musculoskeletal Ultrasound Symposium. Indian J Radiol and Imaging 2007; 17(3):194-200.

[4] Joseph O. de Jesus, Laurence Parker, Andrea J. Frangos, Levon N. Nazarian. Accuracy of MRI, MR Arthrography, and Ultrasound in the Diagnosis of Rotator Cuff Tears: A Meta-Analysis. AJR 2009; 192:1701-1707.

[5] Alan D. Massengill, Leanne L. Seege, Lawrence Yao, Amilcare Gentili, Ronald C. Shnier, Matthew S. Shapiro, Richard H. Gold. Labrocapsular ligamentous complex of the shoulder: Normal Anatomy, Anatomic Variation and Pitfalls of MR Imaging and MR Arthrography. Radiographics 1994; 14: 1211-1223.

[6] Farley TE, Christian NH, Lynn S et al. Full Thickness Tears of the Rotator Cuff of the Shoulder: Diagnosis with MRI. AJR 1992; 158:347-351.

[7] Rakesh Vijayvargiya, Saurabh Atram, Jalpa Daftary et al ;National Journal of Medical and Dental Research, Oct.-Dec. 2014: Volume-3, Issue-1, Page 38-43.

[8] Shrestha MS, Alam A. A Comparative Evaluation of Rotator Cuff Injuries of the Shoulder joint using High Resolution ultrasound and MRI. Medical Journal of Shree Birendra Hospital 2011;10(1):9-14.

[9] Crass JR, Craig EV, Feinberg SB. Ultrasonography of rotator cuff tears: A review of 500 diagnostic studies. J Clin Ultrasound 1988;16:313-27.

[10] Teefey SA, Rubin DA, Middleton WD, Hildebolt CF, Leibold RA, Yamaguchi $\mathrm{K}$, et al. Detection and quantification of rotator cuff tears: Comparison of ultrasonographic, magnetic resonance imaging, and arthroscopic findings in seventy-one consecutive cases. J Bone Joint Surg Am 2004;86-A:708-16.

[11]Zlatkin MB, Reicher MA, Kellerhouse LE, McDade W,

\section{Volume 6 Issue 7, July 2017 www.ijsr.net}




\section{International Journal of Science and Research (IJSR) \\ ISSN (Online): 2319-7064}

Index Copernicus Value (2015): 78.96 | Impact Factor (2015): 6.391

Vetter L, Resnick D, et al. The painful shoulder: MR imaging of the glenohumeral joint. J Comput Assist Tomogr 1988;12:995-1001.

[12]Rakesh Vijayvargiya, Saurabh Atram, Jalpa Daftary et al ;National Journal of Medical and Dental Research, Oct.-Dec. 2014: Volume-3, Issue-1, Page 38-43.

[13] Read JW, Perko M. Shoulder ultrasound: Diagnostic accuracy for impingement syndrome, rotator cuff tear, and biceps tendon pathology. J Shoulder Elbow Surg 1998;7:264-71.

[14] Goldberg JA, Bruce WJ, Walsh W, Sonnabend DH. Role of community diagnostic ultrasound examination in the diagnosis of full-thickness rotator cuff tears. Anz J Surg 2003;73:797-9.

[15] van Holsbeeck MT, Kolowich PA, Eyler WR, Craig JG, Shirazi KK, Habra GK, et al. US depiction of partialthickness tear of the rotator cuff. Radiology 1995;197:443-6.

[16] Wiener SN, Seitz WH Jr. Sonography of the shoulder in patients with tears of the rotator cuff: Accuracy and value of selecting surgical options. AJR Am J Roentgenol 1993;160:103-7. 